\title{
FROTA ATUAL DE TRATORES POR TEMPO DE USO NO BRASIL
}

\author{
Actual Brazilian tractors fleet by time of use
}

\author{
Sabrina Dalla Corte Bellochio1*; Airton dos Santos Alonço²; Francieli de Vargas³; Marília Boff de Oliveira ${ }^{4}$. \\ ${ }^{1}$ Engenheira Agrônoma, Discente no Programa de Pós-graduação em Engenharia Agrícola na Universidade Federal de Santa \\ Maria (UFSM), e-mail: *bellochiosabrinad@hotmail.com \\ ${ }^{2}$ Engenheiro Agrícola, Professor da Universidade Federal de Santa Maria (UFSM), e-mail: airtonalonco@gmail.com \\ ${ }^{3}$ Engenheira Florestal, Discente no Programa de Pós-graduação em Engenharia Agrícola na Universidade Federal de Santa Maria \\ (UFSM), e-mail: devargasfrancieli@gmail.com \\ ${ }^{4}$ Tecnóloga em Produção de Grãos, Discente no Programa de Pós-graduação em Engenharia Agrícola na Universidade Federal \\ de Santa Maria (UFSM), e-mail: marilia.boffdeoliveira@gmail.com
}

Artigo enviado em 21/08/2017, aceito em 11/09/2017 e publicado em 29/09/2017.

\begin{abstract}
Agriculture is fundamental to the country economic and social development. The agricultural mechanization, with tractors participation, allows to increase the cultivated areas or the production scale, then, the Brazilian tractors manufacture began in 1960, with the installation of the local industry. This allowed a new direction in the productive activities, which incorporated new techniques and more productive equipment, to increase the operational efficiency. This study aims to calculate and demonstrate the Brazilian tractors fleet evolution in terms of composition by time of use in the period from the installation of the national tractor industry until 2016. For this composition, were used the annual data of agricultural tractor sales provided from ANFAVEA. The analysis showed that sales follow economic cycles, with peaks in the 70s and 2010. It is also possible to observe that Brazil has almost one million tractors and currently, it has the youngest fleet of the last 29 years, which began its renewal from 2000, by credit related policies.
\end{abstract}

Keywords - Mechanization, fleet composition, renewal.

Resumo - A agricultura é fundamental para o desenvolvimento econômico e social do país. Dessa forma, a mecanização agrícola, com auxílio de tratores, permite ampliar as áreas cultivadas ou a escala de produção, sendo que a manufatura das primeiras unidades de tratores no Brasil se iniciou em 1960, com a instalação da indústria local. Isso possibilitou um novo direcionamento às atividades produtivas do país, que passaram a incorporar novas técnicas e equipamentos mais produtivos, com vistas à eficiência operacional. O objetivo deste estudo foi calcular e demonstrar a evolução da composição da frota brasileira de tratores por faixas de tempo de uso desde a instalação da indústria de tratores no país até o ano de 2016. Para essa composição, foram utilizados os dados anuais de vendas de tratores agrícolas, divulgados pela ANFAVEA. A análise demonstrou que as vendas acompanham os ciclos econômicos, apresentando picos na década de 70 e de 2010. Ainda, é possível observar que o Brasil apresenta, aproximadamente, um milhão de tratores e, atualmente, possui a frota mais jovem dos últimos 29 anos, a qual iniciou sua renovação a partir do ano 2000, por políticas de acesso ao crédito.

Palavras-chave - Mecanização, composição da frota, renovação.

\section{INTRODUÇÃO}

Sabe-se que o agronegócio é de relevância no contexto do desenvolvimento econômico e social do país (NIELS, 2016). Seu fortalecimento ocorreu a partir da década de 50, com a adoção de inovações tecnológicas (AVILA; GRIEBELER; BRUM, 2015). Essa prática se acentuou a partir da década de 1960, principalmente no Sul e Sudeste, e se expandiu para outras regiões, sobretudo a partir da década de 1970 (TEIXEIRA, 2005). Pode-se afirmar que a mecanização agrícola brasileira avançou quando foi instituído o Plano Nacional da Indústria de Tratores de Rodas, sendo que a produção das primeiras unidades nacionais sobreveio em 1960. A partir disso, houve incentivos para a instalação de empresas estrangeiras e a proibição da importação de tratores (NETO, 1985).

A expansão agrícola e a introdução da atividade mecanizada fizeram com que desenvolvesse, proporcionalmente, o mercado de máquinas a fim de suprir 
a demanda interna do país (CASTRO, 2004; SOLOGUREN, 2015). Esse segmento, embora não tendo atingido todas as regiões brasileiras de maneira homogênea (VASCONCELOS; SILVA; MELO, 2013), representa um dos mais importantes no agronegócio brasileiro. Isso ocorre devido à complexidade tecnológica aplicada a máquinas e implementos, ao alto investimento financeiro tanto por parte do fabricante, que visa ao desenvolvimento de novas tecnologias a fim de atender o mercado, quanto pelo consumidor final na busca de eficiência operacional.

Visando à sustentabilidade e à segurança alimentar, a produção agrícola brasileira precisou ser otimizada a partir da década de 70, pelo crescimento populacional e maior demanda por alimentos (MOLIN; AMARAL; COLAÇO, 2015). Isso ocorreu com o aumento da área cultivada, desbravamento de fronteiras agrícolas, implantação de novas tecnologias e práticas de cultivo. A associação dessas práticas possibilitou a produção em escala, elevando o Brasil a um dos maiores produtores de soja do mundo (ESPÍNDOLA; CUNHA, 2015).

$\mathrm{Na}$ mecanização agrícola, as inovações tecnológicas demandaram uma renovação da frota de tratores para proporcionar a compatibilidade, pois estas não podem ser adaptadas em máquinas antigas. Além disso, com a abertura de novas fronteiras agrícolas e com o desenvolvimento da agricultura extensiva, é possível notar o aumento da demanda por máquinas com maior potência e automação em busca da alta produtividade e da redução dos custos de produção (FILHO; FELIPE, 2007; VIAN et al., 2013).

Segundo relatório espanhol MAPAMA (2006), os custos relacionados ao maquinário agrícola decorrem, principalmente, em função do consumo de combustível, de óleos e de lubrificantes, por trocas de filtros, de pneus e por reparos. A diferença no custo de utilização e na manutenção de tratores com menos de cinco anos e com mais de 20 anos é superior a $20 \%$. Assim, a análise da viabilidade do equipamento na frota, deve considerar, para compor a vida útil do trator, sua economia, confiabilidade, atendimento a padrões ambientais e de segurança requeridos. Mialhe (1974 apud COSENTINO, 2004) define a vida útil como o tempo que decorre entre a compra do equipamento e sua rejeição como sucata, no entanto, deveria ser visto como seu tempo de uso econômico.

Pesquisas têm evidenciado os fatores que atuaram ao longo dos anos no crescimento da frota brasileira de tratores, entretanto, o presente estudo tem como proposta calcular e demonstrar a evolução da composição da frota brasileira de tratores por faixas de tempo de uso desde a instalação da indústria de tratores no país até o ano de 2016, contribuindo para a elaboração de inferências que possam auxiliar em pesquisas futuras.

\section{MATERIAL E MÉTODOS}

\section{Material}

A pesquisa foi realizada por meio dos dados anuais de vendas de tratores agrícolas de rodas no Brasil. Estes foram obtidos pelo site da Associação Nacional de
Fabricantes de Veículos Automotores (ANFAVEA), na sessão séries históricas, por via do arquivo “Séries_Máq_Agri\&Rodo.xls". O período utilizado para a análise compreende um total de 56 anos, referindo-se ao ano de 1960 a 2016.

\section{Metodologia}

O planejamento da mecanização e a intensificação do uso do maquinário agrícola apresenta variações entre propriedades rurais. Esse fato está interligado à grande heterogeneidade na extensão territorial e aos inúmeros cultivos agrícolas que o Brasil apresenta. Além disso, inexistem no Brasil programas para retirar do campo tratores em mau estado de conservação. Nesse aspecto, Cosentino (2004) e Debiase et al. (2004) apontam o uso de tratores com mais de 20 anos.

No presente estudo, foi considerada uma vida útil de 30 anos do produto. Com isso, determinou-se a frota em cada ano, relacionando-se as unidades vendidas de 1960 até 2016. A composição da frota foi realizada por meio de uma planilha eletrônica, no formato Microsoft Excel ${ }^{\circledR}$, com a soma das unidades vendidas e, concomitantemente, dividida em seis faixas de tempo de uso a considerar, sendo estas de: 0 a 5 anos; 6 a 10 anos; 11 a 15 anos; 16 a 20 anos; 21 a 25 anos e 26 a 30 anos. Por exemplo: Referente à composição, a partir de 1990, as primeiras unidades vendidas em 1960 completaram 30 anos da data da venda, assim, estas não foram mais consideradas no cálculo dos anos subsequentes.

\section{Análise}

Com a divisão por faixas, é possível analisar, em cada ano, a composição da frota por tempo de uso, suas variações e evolução ao longo do tempo. Assim, o total de tratores que compõem a frota em determinado ano está com sua composição representada em seis faixas de tempo, desde o ano de sua venda até 30 anos posteriores. Essa composição foi analisada e será discutida quanto à sua evolução nesse período.

\section{RESULTADOS E DISCUSSÃO}

Os registros de vendas de tratores no país, conforme ANFAVEA (2017), iniciaram-se no ano de 1960, quando apenas 37 tratores foram vendidos no mercado brasileiro, enquanto que, no ano de 1961, esse número passou para 1.679 unidades, sendo que o pico de vendas da década foi 11.535, em 1964.

$\mathrm{Na}$ década de 70, ocorreu o auge da comercialização, com a média de 40.753 unidades anuais, destacando-se o ano de 1976 com a venda expressiva de 62.700 tratores. Esse marco foi superado apenas 37 anos após, em 2013, quando os números voltaram a subir depois de um período de declínio das vendas.

As décadas de 80 e 90 não superaram os números da década anterior. Já na primeira década do século XXI, o ano de 2009 apresentou o maior número de tratores negociados, com 45.437 unidades, representando a 
retomada crescente das vendas, culminando, em 2013, com 65.089 tratores. Essa evolução das vendas anuais de tratores, que compuseram este estudo da frota nacional, está representada na Figura 01.

Correlacionando-se os dados de vendas ao longo dos anos, calculou-se a frota brasileira de tratores agrícolas, conforme a Figura 02. Nos últimos 40 anos, tal frota apresentou um aumento de $274 \%$, ressaltando que os anos de 2000, 2003, 2014 e 2015 foram os que apresentaram maiores números, sendo que, atualmente a frota é constituída por 944.438 unidades.

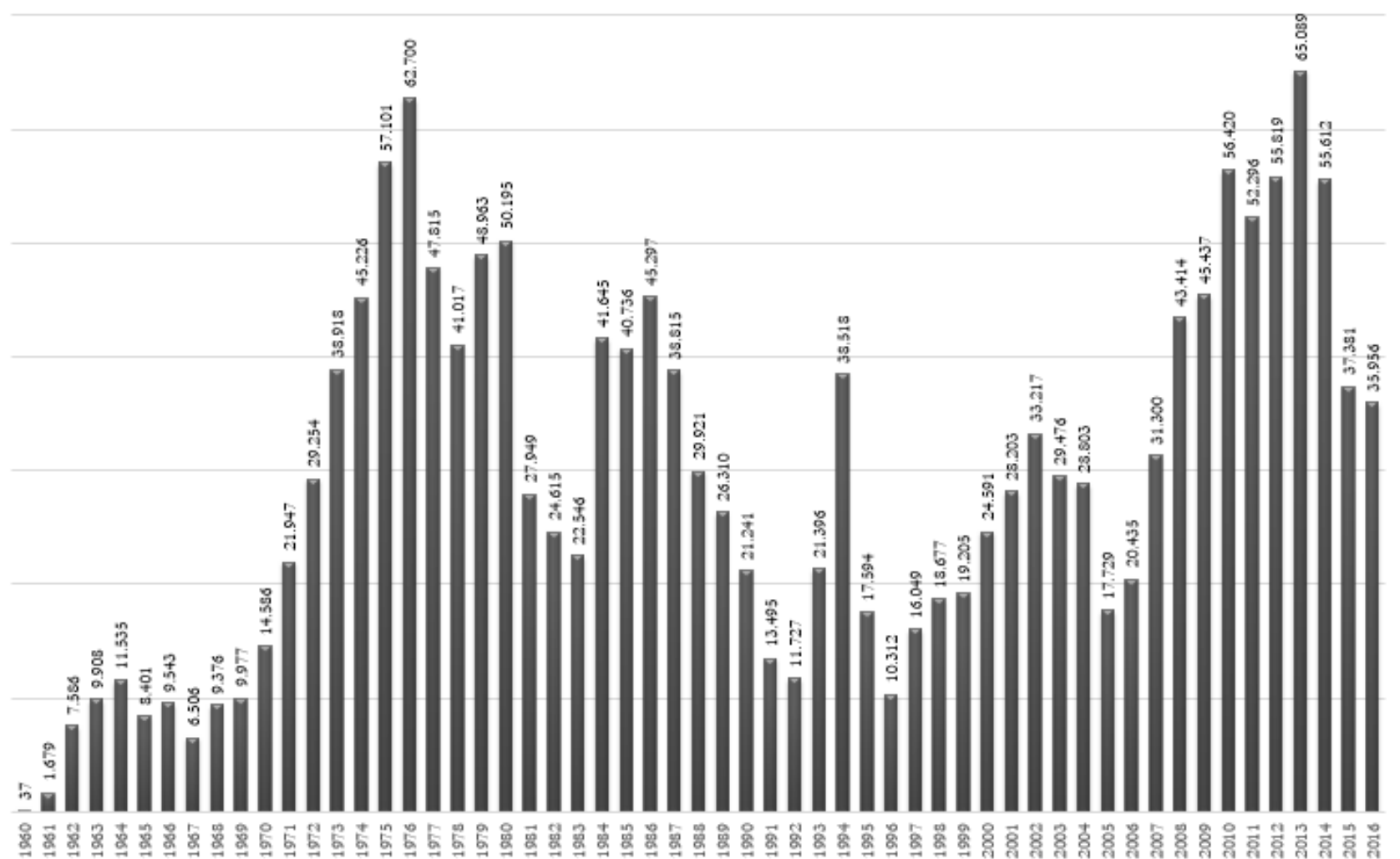

Figura 1: Total de tratores vendidos no Brasil anualmente.

Os tratores entre 0 e 10 anos de utilização correspondiam a 478.724 unidades em 2016, o que equivale, praticamente, à metade da frota total. No mesmo ano, tratores entre 26 e 30 anos representavam 129.782 unidades, sendo este o menor número dos últimos 18 anos, segundo a Figura 02. A análise da composição percentual da frota por tempo de uso indica que o período compreendido entre os anos de 1999 e 2009 é o que apresenta a maior quantidade de tratores com tempo de uso acima de 20 anos, sendo superior a $40 \%$.

A partir desse período, a faixa de tratores com tempo de uso acima de 20 anos expressa um decréscimo contínuo ao longo dos anos, chegando a $25 \%$ em 2016. Isso representa que, no último ano, $75 \%$ dos tratores em uso no Brasil têm menos que 20 anos.

É importante destacar que, no ano de 2016, o país teve a composição de frota de tratores mais nova dos últimos 30 anos. Naquele ano, os tratores na faixa de zero a 10 anos de uso representavam mais da metade do total da frota, com 51\%, sendo este o maior percentual desde 1986, quando representavam 53\%, exibidos na Figura 03.

Visto que a mecanização permite ampliar as áreas cultivadas ou a escala de produção, a manufatura das primeiras unidades de tratores no Brasil iniciou em 1960, com a instalação da indústria local. Antes desse ano, os equipamentos eram todos importados (NETO, 1985; TEIXEIRA, 2005).

Tal fato vem ao encontro aos dados apresentados na Figura 01, quando as vendas se intensificaram a partir dessa data, no entanto, a década de 1970 apresentou maior desenvolvimento do setor agrário, pois foi impulsionada por políticas de crédito facilitado e direcionadas à elevação do nível tecnológico do setor agrícola (NOGUEIRA, 2001). 


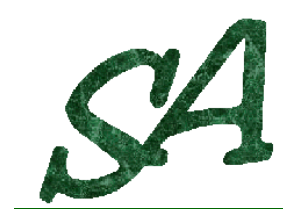

REVISTA SCIENTIA AGRARIA

Versão On-line ISSN 1983-2443

Versão Impressa ISSN 1519-1125

SA vol. $18 \mathrm{n}^{\circ} .3$ Curitiba Jul/Set 2017 p. 154-159

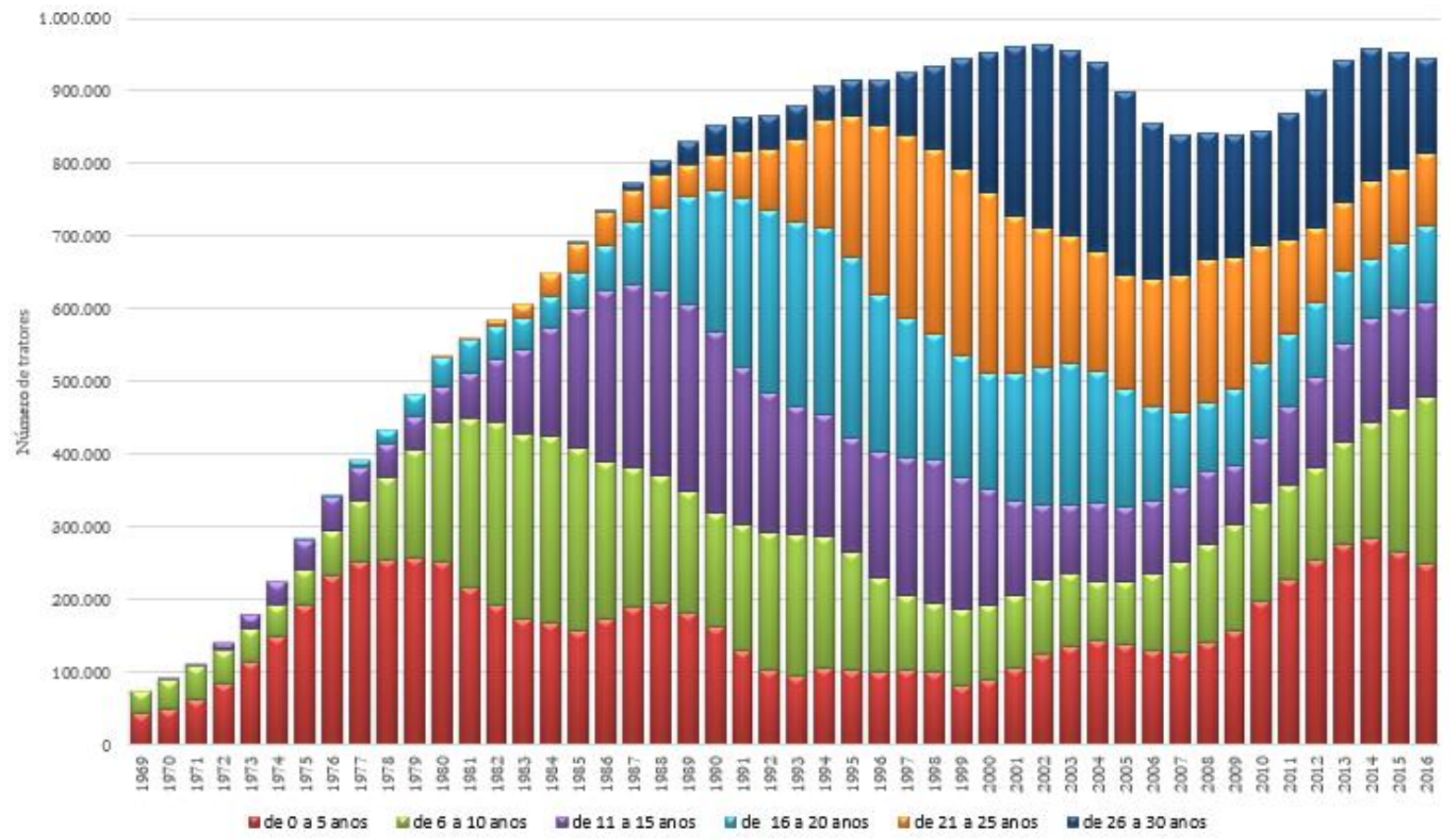

Figura 2: Evolução da frota brasileira de tratores agrícolas, em total de unidades e por faixas de tempo de uso.

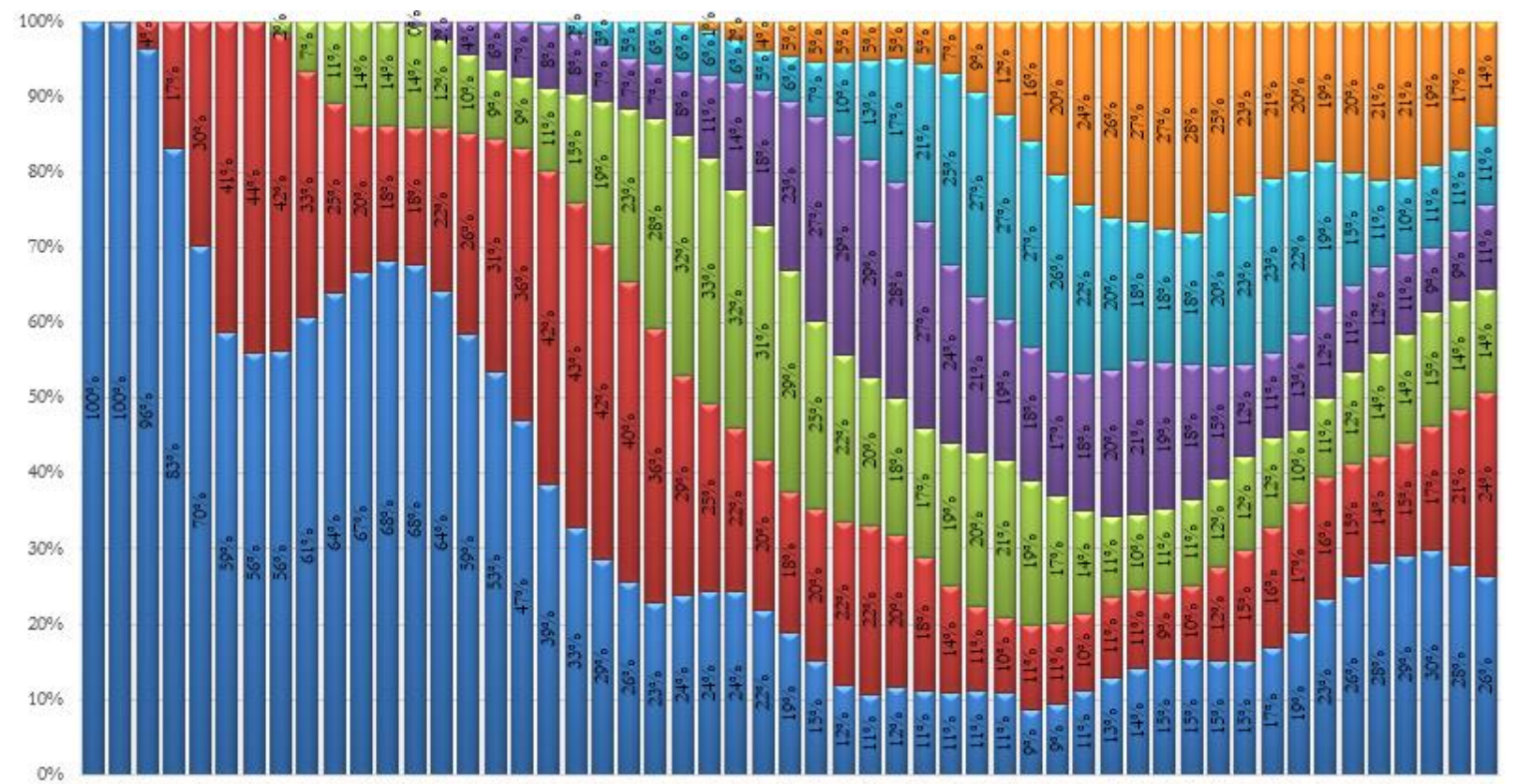

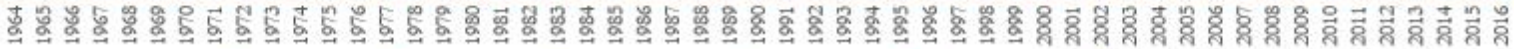

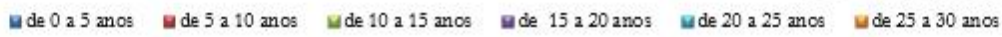

Figura 3: Evolução da composição da frota brasileira de tratores agrícolas em percentual das faixas de tempo de uso

Entretanto, segundo Teixeira (2005), as vendas internas de tratores desde 1985 indicam que estas acompanham os ciclos econômicos do país. O quadro que se apresentou para o setor agrário, nas décadas de 1980 e 1990, é de uma redução dos incentivos agrícolas via crédito rural. O aumento de vendas de tratores ao longo dos anos, apresentado na Figura 01, contribuiu para o aumento da frota do país, porém, isso se demonstrou insuficiente para elevar o índice de mecanização brasileiro aos níveis dos países da Europa e dos Estados Unidos (VIAN et al., 2013). Além do Brasil, países em desenvolvimento, como Argentina, China, Índia, Irã, México e Turquia, foram bemsucedidos na produção local de tratores. A evolução da frota de tratores apresentou um crescimento mais intenso nas 
regiões menos desenvolvidas no período da década de 80 até os anos 2000, segundo Silva e Vian (2017). Quanto à frota, Nogueira (2001) apresentou, para o ano de 1985, um total de 551 mil unidades e, em 1998, um conjunto de 460 mil unidades. Esses dados são, respectivamente, 12\% e 15\% menores dos que os apresentados na Figura 2 para até 20 anos de uso.

Nogueira (2001) destaca que a frota brasileira se apresentava superior à da Argentina (280 mil), mas distante da de países como Canadá (711 mil), Reino Unido (500 mil), França (1,3 milhões) e Estados Unidos (4,8 milhões). Na composição da frota, o relatório espanhol do MAPAMA (2006) corrobora com este estudo, pois a frota de tratores naquele país no ano de 2005 era composta por $23 \%$ de tratores com até 10 anos de uso, enquanto que, no Brasil, apresentava $25 \%$ no mesmo período.

O crescimento no percentual da faixa de tratores com até 10 anos de uso, que teve início no ano 2000 até 2016, observado na Figura 3, pode ser relacionado com os estudos de Molin, Amaral, Colaço (2015). Esses autores destacam que a agricultura de precisão foi impulsionada, no Brasil, a partir do ano 2000, com o foco de abordar a desuniformidade das áreas no espaço e no tempo a partir do uso de inovações tecnológicas de máquinas e equipamentos.

Além disso, o crescente uso de novas tecnologias na propriedade demanda a renovação da frota de tratores, pois os equipamentos apresentam incompatibilidade na conexão com mecanismos presentes nas máquinas antigas. Naquele período, visando à modernização da frota agrícola, a agricultura brasileira foi fomentada por linhas de crédito governamentais especiais por meio do Programa MODERFROTA (BRANDÃO; REZENDE; MARQUES, 2006; VIAN et al., 2013).

Assim, a renovação da frota foi propiciada pelo crescimento na venda de tratores, que conferiu mais conteúdo tecnológico. Portanto, as inovações deram um novo direcionamento às atividades produtivas do país, que passaram a incorporar novas técnicas e equipamentos mais produtivos (TEIXEIRA, 2005).

\section{CONCLUSÃO}

A indústria brasileira de tratores foi fomentada a partir da década de $60 \mathrm{com}$ um número anual crescente de unidades produzidas. Porém, com o passar dos anos, a frota foi envelhecendo, sendo possível notar que, a partir de 1987, mais da metade dos tratores apresentavam tempo de uso superior a dez anos. A partir disso, linhas de crédito especiais fomentaram a modernização da frota e a compatibilidade com novas tecnologias para maior eficiência operacional e redução de custos da produção agrícola. Desta forma, o Brasil apresentou no ano de 2016 a composição de frota mais nova dos últimos 29 anos, com mais da metade dos tratores com até dez anos de uso.

\section{AGRADECIMENTOS}

Os autores agradecem à Coordenação de Aperfeiçoamento de Pessoal de Nível Superior (CAPES) e ao Conselho Nacional de Desenvolvimento Científico e Tecnológico (CNPQ).

\section{REFERÊNCIAS}

ANFAVEA. Associação Nacional de Fabricantes de Veículos Automotores. 2017. Disponível em: http://www.anfavea.com.br/estat\%oc3\%adsticas.html. Acesso em: 19 jan. 2017.

AVILA D. F., de; GRIEBELER M. P. D.; BRUM A. L. Inovação: a Modernização da Agricultura no Planalto Gaúcho (Brasil). UNOPAR Científica. Ciências Jurídicas e Empresariais, v. 16, n. 2, p. 156-164, 2015. Disponível em: http://pgsskroton.com.br/seer//index.php/juridicas/artic le/view/3316/2987. Acesso em: 20 jun. de 2017.

BRANDÃO, A. S. P.; REZENDE, G. C. de; MARQUES, R. W. da C. Crescimento agrícola no período 1999/2004: a explosão da soja e da pecuária bovina e seu impacto sobre o meio ambiente. Revista Economia Aplicada, v. 10, n. 2, p. 249-266, abril/jun. 2006. Disponível em: http://www.scielo.br/pdf/ecoa/v10n2/a06v10n2.pdf. Acesso em: 22 abr. 2017.

CASTRO, B. H. R. Estratégias de Inovação: um estudo na indústria de máquinas e implementos agrícolas no Brasil. Dissertação (Mestrado em Administração). Instituto COPPEAD de Administração da Universidade Federal do Rio de Janeiro - UFRJ, Rio de Janeiro. 125 p., set. 2004. Disponível

em: http://www.coppead.ufrj.br/upload/publicacoes/Bernard o_Castro.pdf. Acesso em: 11 maio 2017.

COSEnTINO, R. M. A. Modelo empírico de depreciação para tratores agrícolas de rodas. Dissertação (Mestrado em Agronomia). Escola Superior de Agricultura Luiz de Queiroz - Universidade de São Paulo, Piracicaba, SP. 80 p., 2004.

DEBIASE, H.; SCHOLOSSER, J. F.; PINHEIRO, E. D. Características ergonômicas dos tratores agrícolas utilizados na região central do Rio Grande do Sul. Revista Ciência Rural, v. 34, n. 6, p. 1807-1811, 2004.

ESPÍNDOLA, C. J.; CUNHA, R. C. C. A dinâmica geoeconômica recente da cadeia produtiva da soja no Brasil e no mundo. GeoTextos, v. 11 n. 1, p. 217- 238, jul. 2015.

FERREIRA FILHO J. B. \& FELIPE F.I. Crescimento da produção agrícola e o consumo de tratores de rodas no Brasil entre 1996 - 2005. In: XLV Congresso da Sociedade Brasileira de Economia, Administração e sociologia Rural. $2007 . \quad$ Disponível em: https://www.agrolink.com.br/downloads/88756.pdf. Acesso em: 02 jun. 2017.

MAPAMA. Ministério da Agricultura e Pesca, Alimentação e Meio Ambiente. Espanha, 2006. Análisis del parque 
nacional de tractores agrícolas 2005 - 2006. 51 p. Disponível em:

http://www.mapama.gob.es/es/agricultura/temas/medios -de-produccion/parque_tractores_tcm7-1122.pdf. Acesso em: 19 jun. 2017.

MOLIN, J. P.; AMARAL, L. R.; COLAÇO, A. F. Agricultura de precisão. 1. ed., São Paulo, SP. Oficina de Textos, 2015. 224 p.

NETO J. A. A indústria de máquinas agrícolas no Brasil Origens e evolução. Revista Administração Empresarial, v. 25, n. 3, p. 57-69, jul./set. 1985. Disponível em: http://www.scielo.br/pdf/rae/v25n3/v25n3a05.pdf. Acesso em: 15 maio 2017.

NIELS, S. Public-private re-alignments: the role of structural economic transformations in spurring the joint international engagement of agribusiness and the Brazilian State. Política \& Sociedade - Florianópolis, v. 15, n. 32, p. 204-229, jan./abr. 2016. Disponível em: http://dx.doi.org/10.5007/2175-7984.2016v15n32p204. Acesso em: 16 ago. 2017.

NOGUEIRA A. C. L. Mecanização na agricultura brasileira: uma visão prospectiva. Caderno de Pesquisas em Administração, São Paulo, v. 8, n. 4, out./dez. 2001.

SILVA, R. P. da; VIAN, C. E. de F. O mercado mundial de máquinas agrícolas: distribuição regional e padrões de comércio internacional. Revista Espacios, v. 38, n. 1, p. 28, 2017. Disponível em: http://www.revistaespacios.com/a17v38n01/17380128.ht ml. Acesso em: 5 jun. 2017.
SOLOGUREN, L. Demanda mundial cresce e Brasil tem espaço para expandir produção. Visão agrícola. Universidade de São Paulo, SP, ano 9, jul./dez. 2015. p.8$11 . \quad$ Disponível em: http://www.esalq.usp.br/visaoagricola/sites/default/files/ Esalq-VA13-Milho.pdf. Acesso em: 15 jul. 2017.

TEIXEIRA, J. C. Modernização da agricultura no Brasil: impactos econômicos, sociais e ambientais. Revista Eletrônica da Associação dos Geógrafos Brasileiros, Seção Três Lagoas Três Lagoas-MS, v. 2, n. 2, p. 21-42, ano 2, set. 2005.

VASCONCELOS, K. S. L. de; SILVA, T. J. J. da; MELO, S. R. S. Mecanização da agricultura: demanda por tratores de rodas e máquinas agrícolas nos estados da região nordeste. Revista em Agronegócios e Meio Ambiente, v.6, n.2, p. 207-222, maio/ago. 2013.

VIAN, C. E. de F.; ANDRADE JÚNIOR, A. M.; BARICELO, L. G.; SILVA, R. P. Origens, Evolução e Tendências da Indústria de Máquinas Agrícolas. Revista de Economia e Sociologia Rural, Piracicaba, SP, v. 51, n. 4, p. 719-744, out./dez. 2013. Disponível em: http://www.scielo.br/pdf/resr/v51n4/a06v51n4.pdf. Acesso em: 6 jun. 2017. 